\title{
Can Neutron Beam Components and Radiographic Image Quality be determined by the
} Use of Beam Purity and Sensitivity Indicators?

Domanus, Joseph Czeslaw

Publication date:

1986

Document Version

Publisher's PDF, also known as Version of record

Link back to DTU Orbit

Citation (APA):

Domanus, J. C. (1986). Can Neutron Beam Components and Radiographic Image Quality be determined by the Use of Beam Purity and Sensitivity Indicators? Risø National Laboratory. Risø-M No. 2579

\section{General rights}

Copyright and moral rights for the publications made accessible in the public portal are retained by the authors and/or other copyright owners and it is a condition of accessing publications that users recognise and abide by the legal requirements associated with these rights.

- Users may download and print one copy of any publication from the public portal for the purpose of private study or research.

- You may not further distribute the material or use it for any profit-making activity or commercial gain

- You may freely distribute the URL identifying the publication in the public portal

If you believe that this document breaches copyright please contact us providing details, and we will remove access to the work immediately and investigate your claim. 
KISg-R-2579

CAN NEUTRON BEAM COMPONENTS AND RADIOGRAPHIC IMAGE QUALITY BE DETERHINED BY THE USE OF BEAM PURITY AND SENSITIVE INDICATORS?

J. C. Domanus

Abstract. In the Euratom Neutron Radiography Working Group Test Program beam purity and sensitivity indicators, as prescribed by the ASTM E 545-81 were used together with the NRWG beam purity indicator-fuel and calibration fuel pin. They were radiographed together at neutron radiography facilities of the European Community. The direct, transfer and track-etch methods using different film recording materials were used. Neutron beam components were calculated from film density measurements under the beam purity indicators and radiographic image quality was assessed by visual examination of the sensitivity indicator. Results obtained under the NRWG Test Program are summarized and compared.

INIS Descripterg: CALIBRATION; DENSITY; FUEL PINS; HALIDES; IMAGES; NEUTRON BEAMS; NEUTRON RADIOGRAPHY; NITROCELLULOSE; PHOTOGRAPHIC FILMS; SENSITIVITY; SILVER COMPOUND; STANDARDIZATION; THERHAL NEUTRONS.

Accepted for presentation at the second world conference on Neutron Radiography, Paris, 16-20-06.1986.

May 1986

Risø Nationai Laaboratory, DR-4000 Roskilde, Denmark 
ISBN 87-550-1226-4

ISSN 0418-6435

Grafisk Service, Riso 1986 
CONTENrS

Page

1. IRTRODUCTIOA $\ldots \ldots \ldots \ldots \ldots \ldots \ldots \ldots \ldots \ldots \ldots \ldots \ldots \ldots \ldots \ldots \ldots \ldots .5$

2. MEUTRON BEAH COAPOAELTS $\ldots \ldots \ldots \ldots \ldots \ldots \ldots \ldots \ldots \ldots \ldots \ldots$ 7

2.1. Thermal neutron content measured by the direct method ......................... 8

2.2. Thermal neutron content measured by the transfer method .......................... g

2.3. Thermal neutron content neasured by the track-etch method $\ldots . . \ldots \ldots \ldots \ldots \ldots \ldots \ldots \ldots \ldots \ldots$

2.4. Thermal neutron content measured by the direct method on single coated silver hal ide film ............................... 10

3. SEHSITIVITY OP DETAIL VISIBILITY $\ldots \ldots \ldots \ldots \ldots \ldots \ldots \ldots \ldots$

4. RADIOGRAPAIC CATECORIES ..................... 13

5. GAMHA RAY COMTENT ........................ 13

6. L/d RATIO .................................. 14

7. Calibration fuel PIN $\ldots \ldots \ldots \ldots \ldots \ldots \ldots \ldots \ldots \ldots \ldots \ldots \ldots . \ldots . \ldots$

8. DETERMINIEG IMAGE QUALITY .................... 15

9. conclustons $\ldots \ldots \ldots \ldots \ldots \ldots \ldots \ldots \ldots \ldots \ldots \ldots \ldots \ldots \ldots \ldots \ldots$

REPERENCES $\ldots \ldots \ldots \ldots \ldots \ldots \ldots \ldots \ldots \ldots \ldots \ldots \ldots \ldots \ldots \ldots \ldots \ldots \ldots \ldots \ldots . \ldots 18$ 



\section{INTRODUCTION}

At present there are only two national standards dealing with the problem of radiographic image quality in neutron radiography: The first one is the ASTM E545 III and the second the AFNOR A09-220 121 .

In the first issue of the ASTME 545 standard from 1975 four types of sensitivity indicators were listed. In the second issue (from 1981) only one, different, sensitivity indicator is recommended for use.

The ASTM Standard from 1981 is now under revision. A draft E545-85 of this revision $|3|$ was taken into account in preparing of this paper.

Both in the 1975 as well as the 1981 edition of E545 the use of the beam purity indicator was limited to radiography with metal conversion screens and eilver halide film. In the 1985 draft the whole 6545 standard is limited to the direct thermal neutron radiography and the use of the BPI to metallic conversion screens and single emulsion silver halide films. In all the three editions of E545 it is stated the the "use of alternative detection systems may produce densitometric readings which are not directly comparable to the formulas" given in the standard.

No doubt the nitrocellulose film falls into the category of "alternative detection systems".

No such restrictions are given to the use of the sensitivity indicator, so according to the 1985 E545 draft it can be used within the direct thermal neutron radiographic testing, also with double emulsion silver halide films.

The ASTM standard |l| explicity states that "requirements expressed in this method are intended to determine the quality of the neutron radiographic images". The sensitivity indicator si 
is described as a device for quantitative determination of radiographic quality". The "sensitivity level is determined by visually analyzing the image of the sensitivity indicator".

This is done by "evaluating the image of the sensitivity indicator and assessing a numerical value" to it.

The whole procedure consists of determining the number of visible consecutive holes on the neutron radiographs of the SI and the number of visible gaps (Al shims between acrylic steps).

The number of visible holes (B) together with the number of visible gaps (G) (Al shims) is thereafter used to determine the neutron radiographic category.

Further information necessary for the determination of those categorjes is obtained from densitometric measurements under various parts of the Beam Purity Indicator-BPI.

There is still another information which ought to be retrieved from neutron radiographs of the $S I$ by visual examination. It is the number of visible holes $(\mathrm{Pb})$ in the shim under the lead steps $D$ of the $S 1$.

According to 7.14 of the ASTK E545-85: "Visually inspect the image of the lead steps in the sensitivity indicator. If the $0.25 \mathrm{~mm}$ holes are not visible, the exposure contribution from gamma radiation is very high. An evaluation should be made to determine if the radiographic quality is sufficient for the required inspection".

The ASTM standard describes the purpose of using of the beam purity indicator in the following way (53.1): "The BPI is designed to yield information concerning neutron beam and image system parameters that contribute to film exposure and thereby affect overall image quality. In addition the beam purity indicator can be used to verify the day-to-day consistency of neutron radiographic quality". Furthermore formulas are given in the standard to calculate neutron beam constituents from density measurements of the BPI. 
This ASTM method of determining neutron radiographic image quality by the use both of the beam purity indicator (BPI) and sensitivity indicator (SI) seems rather awkward and complicated.

In other fields of industrial radiography ( $X$-and gamma-radiography) different image quality indicators are used.

The assessment of radiographic image quality by the use of those IQI's is, however, limited to visual examination of wires, holes or steps visible on radiographs. No film density measurements are prescribed and no calculations are performed therefrom. Although in $X$ - and gamma-radiography the radiographic image quality depends of such factors as e.g. the spectral composition of the radiation bean, and of the scattered radiation reaching the radiograph, those factors are not determined by the use of the IQI's. The user of a radiograph is interested only of the final radiofraphic guality, whereas the information about the factors influencing this quality are of interest only to the producer of the radiograph.

\section{NEUTRON BEAM COMPONENTS}

As mentioned above, according to ASTM E545, the beam purity indicator (BPI) serves to determine the neutron beam components. In the 1981 version of the 2545 the use of BPI was restricted to the use of silver halide film and metal conversion screens.

Now, according to the 1985 drafi of the 2545 it is further restricted to the direct method and single coated silver halide film.

The NRWG Test Program was started before this 1985 draft was issued. It was decided then to test the usefulness of the BPI. As the NRWG is interested only in neutron radiography of nuclear reactor fuel, which is mainly radiographed in post- 
irradiation examination, a modification of the ASTM BPI was designed by the NRWG. It is the beam purity indicator-fuel (BPI-F), not meant to determine the gamma-ray content of the neutron beam (as the irradiated fuel is itself a source of strong gamma-radiation).

Both the BPI and BPI-F (together with the SI and CFP-El) were neutron radiographed at all NR facilities participating in the NRwg Test Program. Both the direct as well as the transfer method were used with metal converter screens. Although the ASTM method is restricted only to silver halide film exposures were made also on nitrocellulose film. Those radiographs were thereafter copied on high contrast silver halide film and also viewed through polarizing filters.

In both instances the images of the nitrocellulose film looked similar to those made on silver halide film. Therefore it was worth comparing the neutron beam component findings using all those different recording methods.

\subsection{Thermal neutron content measured by the direct method}

Throughout the NRWG Test Programn three brands of silver halide film were used both for the direct as well as the transfer method. They were the single coated Rodak Industrex SR film, double coated Agfa-Gevaert structurix D4 and Rodak Industrex $M$ film.

In all instances where the direct method (with $0.25 \mu \mathrm{m} \mathrm{Gd}$ ) was used highest content of thermal neutrons was always calculated from density measurements of the $S R \mathrm{film}$, and lowest for the D4 film. For the BPI this difference could be as great as 418 whereas for the BPI-F the greatest difference was 328 . The thermal neutron content values calculated from densities under the BPI-P were always greater than those from the BPI. 


\subsection{Thermal neutron content_measured by the transfer method}

The same phenomenon was observed when using the transfer method (100 $\mathrm{m} \mathrm{Dy}$ ) and the same silver halide film. Here also the highest values of thermal neutron content were calculated for the SR film and lowest for D4 film.

In general the percent differences were lower than those for the direct method. As with the direct metod the absolute values calculated for the BPI-F were in general higher than those for the BPI.

2.3. Thermal neutron content measured by the track-etch method

As mentioned before neutron radiographs made on nitrocellulose film and copied on high contrast silver halide film or viewed through polarizing filters can be compared with those taken on silver halide film.

Whereas the viewing through polarizing filters gives quite erroneous results as regards the measurements of thermal neutron content, the copies of nitrocellulose film on high contrast silver halide film can be used for that purpose.

During the NRWG Test Program different etching conditions were investigated. At Riso the nitrocellulose films were etched at $20^{\circ} \mathrm{C}$ for $21 \mathrm{~h}$ and at $50^{\circ} \mathrm{C}$ for $45 \mathrm{~min}$. In most instances the second etching mode gave slightly higher values of the thermal neutron content than the first mode.

With the track-etch method two $\mathrm{film} / \mathrm{monverter}$ combinations were used for the nitrocelulose film. In the first the CN85 $B$ film coated on both sides with converter was used. The second consisted of the CN85 film sandwiched between two BNl converters. The CN85+BNl film/converter combination gave higher values of the thermal neutron content. 
As the nitrocellulose film can be compared with the silver halide film used with the transfer method such comparison was made between the SR/DY silver halide $f i l m /$ converter combination of the transfer method and the CN85+BNl nitrocellulose film/converter combination, copied on high contrast silver halide film. They both give the highest readings of thermal neutron content for the exposure methods under comparison. In many instances the results reached for the sR/Dy transfer method and the CN85+BNl track-etch method were very similar.

\subsection{Thermal neutron content measured by the direct method on single coated silyer halide film.}

As mentioned before the draft ASTM E545-85 standard limits the use of the BPI to the direct method using single coated silver halide film and metal converter.

To check the consistency of measuring results by the above method 15 BPI neutron radiographs, taken on SR film with the 25 $\mu m$ Gd converter were compared. Those radiographs were taken at the same DRI reactor at Riso with the same fluence but at different period of times. The results of this comparison, reported in $|4|$, are shown on $f i g .1$.

As can be seen the readings of the thermal neutron content are always higher for the BPI than for the BPI-F, and the difference of those varies, as does the mean background film density

The highest variation between the BPI readings is about 208 , for the BPI-F only 98 and for the mean background film density as large as 1.4. Although it is possible that at different operational periods of the DRl the composition of the neutron beam was varied, it is improbable that the variation could reach 208 .

The variations in the background $f 11 \mathrm{~m}$ derisities were no doubt caused instead by the changing neutron beam fluence and not the thermal neutron content. One could, perhaps, look for a 

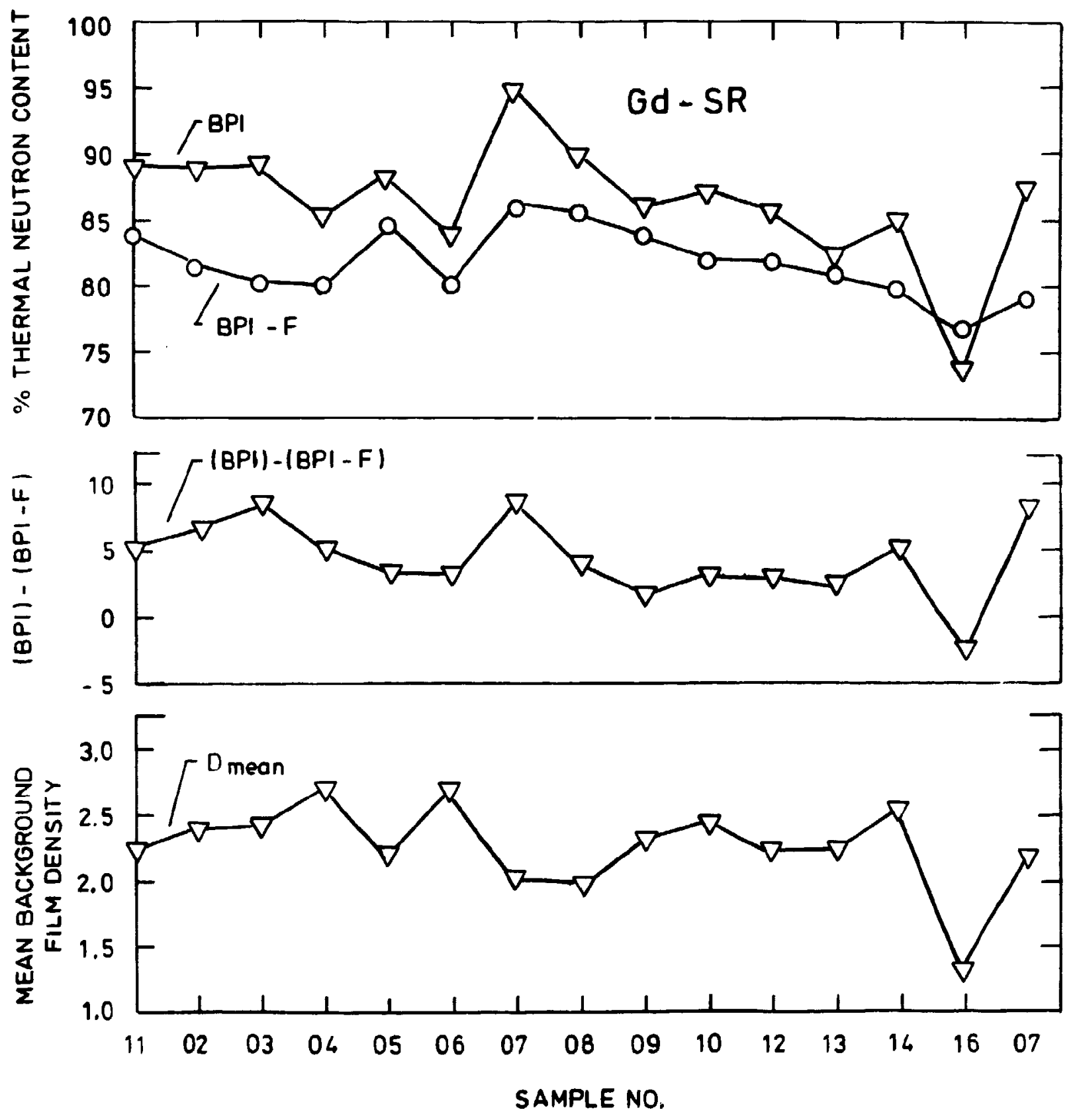

F1g. 1. Thermal neutron content and mean background film densities 
correlation between the thermal neutron content readings and those of the background film density. A. Laporte and G. Bayon have already found such a correlation. According to $|5|$ the readings for the thermal neutron content decrease with increasing film density. This effect could perhaps also explain the variations of thermal neutron content as shown in fig. 1.

3. SENSITIVITY OF DETAIL VISIBILITY

The ASTM sensitivity indicator (SI) was used (exposed together with the BPI and BPI-F) to determine the sensivity level. According to the ASTM one shall visually determine the number of visible Al shims and holes in the acrylic shims of the $S I$. The visual examination of the sI performed during comparison mentioned above has shown that in all instances the 7 Al shims are visible on all neutron radiographs. This wholly supports the statement made in $|5|$ that the $s I$ "is not selective as changes in image quality....do not correspond to the readings of the sensitivity indicator".

Regarding the second information about the sensitivity of detail visibility, which according to ASTi can be retrieved from the image of the SI, one can say that the visibility of the holes in the acrylic shims (under acrylic step-wedge) is more selective than that of the Al shims. Although the $L / D$ ratio has changed considerably from one reactor to another (from 75 to 500 ) the relation between the hole visibility and the L/D was not so direct as one could expect. Obviously other factors (e.g. scattered and gamma radiation) were of importance. 


\section{RADIOGRAPHIC CATEGORIES}

The ASTM designation of quality level includes thermal neutron content and sensitivity level, and according to it neutron radiographic categories are specified. When no designation of quality level is specified by the user the ASTM reguires that neutron radiographs shall be at least category III, which means that the thermal neutron content shall be at least 558, that at least 5 consecutive holes and 5 Al shims cught to be seen in the neutron radiograph of the SI.

However, in the 1985 draft of the ASTM this has been changed admitting also categories IV and $\mathrm{V}$.

Looking from that point of view at the results obtained under the NRWG test program one can see e.g. that at Riso category III could never be reached as 5 consecutive holes could never be seen. The same can be said about the other 8 NR facilities contributing to the NRW Test Program. There, only in very few instances, the 5 th hole could be seen, although the $L / D$ ratio was sometimes as high as 500 .

\section{GAMMA RAY CONTENT}

There are further, rather vague, requirements in the ASTM standard regarding the image quality. It is, e.g. required to visually inspect the image of the lead steps in the sI. If the $0.25 \mathrm{~mm}$ holes are not visible the exposure contribution from gamma radiation is considered very high. All the four $0.25 \mathrm{~mm}$ holes under $\mathrm{Pb}$ steps were never seen on either of the NRWG neutron radiographs, although, e.g. in the Riso DRl facility the gamma contribution in the neutron beam is negligible. It 
proves that the assessment of the gamma contribution from the measurements performed by the use of the BPI and visual examination of the sI are incompatible.

6. L/D RATIO

Another vague requirement of te ASTM standard relates to the judgement of the $L / D$ ratio from the visual comparison of the sharpness of the cadmium rods of the BPI. Such visual examination is very subjective and hard to perform.only by using a travelling microdensitometer the problem can be solved, but as this instrument is relatively expensive it is unavailable in most of the NR facilities. Therefore it is not realistic to recommend its.use in a standard.

7. CALIBRATION FUEL PIN

As described above for the NRWG Test Program three indicators: BPI, BPI-F and SI were produced at Risø. But even the possesion of those three indicators seemed to be insufficient for the image quality control of nuclear radiographs of nuclear fuel. Therefore, the NRWG has followed the statement of the ASTM E545 that: "It is recognized that the only truly valid sensitivity indicator is a material or component, equivalent to the part being radiographed, with a known standard discontinuity (reference standard comparison part)". such a "reference standard comparison part" was designed by the NRWG for nuclear fuel. It was produced at Riso as a calibration fuel pin (CFP-El) and distributed among all the participants of the NRWG. It includes such "standard discontinuities" as pellet-to-pellet and pelletto-cladding gaps (calibrated gaps from 50 to $300 \mu \mathrm{m}$ ). 
Neutron radiographs of the calibration fuel pin were used for the assessment of radiographic image quality by the visual method $|6|$.

The calibration fuel pin CPP-El in its present form cannot directly be recommended for use as an IQI for neutron radiography of nuclear reactor fuel. However, the results reached under the NRWG Test Program, regarding the accuracy of dimensional measurements from the CPP-El, together with the results quoted in $|6|$ will form a basis for designing a proper image quality indicator for neutron radiographs of nuclear reactor fuel.

\section{DETERMINING IMAGE QUALITY}

The title of ASTM E545 implies that by the use of it one can determine radiographic image quality in thermal neukron radiography. For that purpose both the BPI and SI must be used.

As demonstrated above the results obtained with the BPI depend on the exposure and detecting method in use and give different results for the same NR facility.

The indications obtained by the use of the SI about radiographic sensitivity are not selective enough and give not consistent information in that respect.

Besides, the results obtained with the BPI and SI, regarding the gamma-ray content of the neutron beam are often contradictory and the judgement of the $\mathrm{L} / \mathrm{D}$ ratio from the examination of the image of the BPI is practically impossible in routine neutron radiography.

It is not clear why an analysis of nuclear beam components must be included into the procedure of assessing the radiographic image quality of a neutron radiograph. 
The final assessment prescribed by the ASTn E545, by determing neutron radiographic categories is also ambiguous. It requires e.g. trat when no designation of thermal neutron content (frow the BPI readings) and hole and gaps visibilities (from visual assessment of the $S I$ ) is specified by the user then the neutron radiographs shall be at leass category III, IV. or $V$ (category $V$ being the worst of all).

The problem of the usefulness of the ASTH E545 method was also investigated by others.

In the wore extensive study $A$. Laporte and $G$. Bayon $|5|$ have examined three types of X-ray films, exposed with $25 \mathrm{~m}$ GD foil by the direct technique and processed both manually and automatically. The conclusions from those investigations performed using the BPI and si were the following:

- It is impossible to determine the neutron beam components themselves by the use of BPI or BPI-P. because the results of film density measurements give indications about the effect of neutron radiation on the whole irradiation and detection system (collimator, film cassette, film, converter, processing) and do not permit calculation of the neutron beam components separately themselves. It is, e.g. quoted in $|5|$ that the percentage of thermal neutron content can vary by as much as 838 when measured with $X$-ray films of different speed and it also depends on the film density and the processing mode.

- The IS is not selective enough to determine the image quality. As reported in $|5|$ on all neutron radiographs, disregarding the different film brands used, their density and processing mode, all the slits of the sI were visible. Furthermore, the conclusions drawn about the gamma-ray content derived from the visual examination of hoses in the lead shim of the $S I$ contradict the calculations of gamma-ray content from the BPI. similar conclusions were also formulated in $|7|$.

A. Laporte and $G$. Bayon $|5|$ have also investigated the findings obtained with the ASTM BPI from the point of view of film speed 
and density, as well as the wode of processing and have come to the conclusion that "the text of the standard is wholly unsuited to the purpose for which it is intended both from a fundamental point of view and as far as details are concerned". This was also proved by other results quoted in $|4|$. In $|5|$ the same conclusions are also given for determining scattered neutron, gamma and pair production content.

\section{9. conclosions}

1) Both the BPI and BPI-F cannot serve the purpose of determining the neutron beam components of a NR facility. Therefore, they cannot be used for the purpose of comparing various facilities.

2) The assessment of radiographic image quality by the evaluation of the components of the SI is not selective enough if the visible gaps are counted (all are always seen). At the same time it gives an incorrect impression of image quality from the evaluation of visible holes (even with very good $L / D$ more than 4 holes can very seldom be seen).

3) The assessment of the gamma-ray content from the densities under BPI and visual examination of te SI are incompatible.

4) The ASTM standard (even as modified by the NRWG) is unsuited to image quality control in neutron radiography of nuclear fuel.

5) After obtaining detailed result of measurenents performed now on the calibration fuel pin one will be able to draw conclusions about its usefulness for determining the image guality of neutron radiographs of nuclear fuel. 
REPEREMES

I11 ASTM 8545-81. Standard method for determining image quality in thermal neutron radiographic testing.

|2| AFNOR A09 - 220. Neutronographie industrielle. Determination des characteristiques des installations pour controle des pieces non radioactives. Norme experimentale. Septenbre 1982.

$|3|$ ASTM Draft E545-85. Standard method for determining image quality in direct thermal neutron radiographic testing.

I4I J. C. Domanus, P. Gade-Nielsen, J. Olsen - How good are the standards for the image quality in neutron radiography of nuclear fuel? Proceedings of the 7th International Conference on Non Destructive Evaluation in Ruclear Industry. Grenoble, 29.1 - 1.2.1985.

I5I A. Laporte, G. Bayon. determination of image quality in industrial neutron radiography. CEn-PAR. Service des Piles de saclay. Section dexploatation TRITON. 6.203 .2 .

$16 \mid$ J. C. Domanus. Assessment of radiographic image quality by visual examination of neutron radiographs of the calibration fuel pin. Riso-M-2578. April 1986. (To be presented at the 2nd World Conference on Neutron Radiography, Paris, 16.-20.06.86).

I7I H. P. Leeflang. Preliminary assessment of the NRWG test program performed with the Petten neutron radjography facility. ECN-83-074. Petten. May 1983. 
Title and author (s)

Date $1986-05-06$

CAN NEUTRON BEAM COMPONENTS AND RADIOGRAPHIC

IMAGE QUALITY BE DETERMINED BY THE USE OF

BEAM PURITY AND SENSITIVITY INDICATORS?

J. C. Domanus

Department or group

Metallurgy

Group's own registration number (s)

Abstr act

In the Euratom Neutron Radiography Working Group Test program beam purity and sensitivity indicators, as prescribed by the ASTM E545-19EI were used together with the NRwg beam purity indicator-fuel and calibration fuel pin. They were radiographed together at neutron radiography facilities of the European Community. The direct tra-sfer and track-etch methods using different film recording materials were used. Neutron beam comporients were calculated from film density mea surements under the beam purity indicators and radiographic image quality was assessed by visual examination of the sensitivity indicator. Results obtained under the NRWG Test Program are summarized and compared.

Accepted for presentation at the second world Conference on Neutron Radiography, Paris, $16-20.06 .1986$.

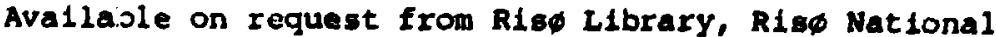

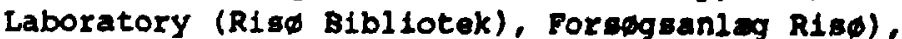
DK-4000 Roskilde, Denmark Telephone: (02) 3712 12, ext. 2262, Telex: 43116 